Article

\title{
Protamine-2 Deficiency Initiates a Reactive Oxygen Species (ROS)-Mediated Destruction Cascade during Epididymal Sperm Maturation in Mice
}

\author{
Simon Schneider ${ }^{1}$, Farhad Shakeri ${ }^{2,3}$, Christian Trötschel ${ }^{4}$, Lena Arévalo ${ }^{1}$, Alexander Kruse ${ }^{5}$ (D) \\ Andreas Buness ${ }^{2,3}$, Ansgar Poetsch ${ }^{4,6,7} \mathbb{0}$, Klaus Steger ${ }^{5}$ and Hubert Schorle ${ }^{1, *}$ \\ 1 Department of Developmental Pathology, Institute of Pathology, University Hospital Bonn, \\ 53127 Bonn, Germany; simon.schneider@ukbonn.de (S.S.); lena.arevalo@ukbonn.de (L.A.) \\ 2 Institute for Medical Biometry, Informatics and Epidemiology, Medical Faculty, University of Bonn, \\ 53127 Bonn, Germany; farhad.shakeri@uni-bonn.de (F.S.); andreas.buness@uni-bonn.de (A.B.) \\ 3 Institute for Genomic Statistics and Bioinformatics, Medical Faculty, University of Bonn, \\ 53127 Bonn, Germany \\ 4 Department of Plant Biochemistry, Ruhr-University Bochum, 44801 Bochum, Germany; \\ christian.troetschel@rub.de (C.T.); ansgar.poetsch@rub.de (A.P.) \\ 5 Department of Urology, Pediatric Urology and Andrology, Section Molecular Andrology, \\ Biomedical Research Center of the Justus-Liebig University Gießen, 35392 Gießen, Germany; \\ Alexander.Kruse@chiru.med.uni-giessen.de (A.K.); klaus.steger@chiru.med.uni-giessen.de (K.S.) \\ 6 Laboratory for Marine Biology and Biotechnology, Qingdao National Laboratory for Marine Science \\ and Technology, Qingdao 266237, China \\ 7 College of Marine Life Sciences, Ocean University of China, Qingdao 266003, China \\ * Correspondence: hubert.schorle@ukbonn.de; Tel.: +49-228-287-16342
}

Received: 29 June 2020; Accepted: 24 July 2020; Published: 27 July 2020

\begin{abstract}
Protamines are the safeguards of the paternal sperm genome. They replace most of the histones during spermiogenesis, resulting in DNA hypercondensation, thereby protecting its genome from environmental noxa. Impaired protamination has been linked to male infertility in mice and humans in many studies. Apart from impaired DNA integrity, protamine-deficient human and murine sperm show multiple secondary effects, including decreased motility and aberrant head morphology. In this study, we use a Protamine-2 (Prm2)-deficient mouse model in combination with label-free quantitative proteomics to decipher the underlying molecular processes of these effects. We show that loss of the sperm's antioxidant capacity, indicated by downregulation of key proteins like Superoxide dismutase type 1 (SOD1) and Peroxiredoxin 5 (PRDX5), ultimately initiates an oxidative stress-mediated destruction cascade during epididymal sperm maturation. This is confirmed by an increased level of 8-OHdG in epididymal sperm, a biomarker for oxidative stress-mediated DNA damage. Prm2-deficient testicular sperm are not affected and initiate the proper development of blastocyst stage preimplantation embryos in vitro upon intracytoplasmic sperm injection (ICSI) into oocytes. Our results provide new insight into the role of Prm2 and its downstream molecular effects on sperm function and present an important contribution to the investigation of new treatment regimens for infertile men with impaired protamination.
\end{abstract}

Keywords: protamines; sperm; infertility; ROS

\section{Introduction}

Male fertility relies on the tightly regulated differentiation of spermatogonial stem cells into flagellated sperm within the seminiferous epithelium of the testis. During spermatogenesis, a series 
of mitotic and meiotic divisions results in the formation of haploid, round spermatids. Extensive cytological remodeling during spermiogenesis generates the characteristic, species-specific sperm morphology. Canonical histones are replaced by testis-specific histone variants and transition proteins, which finally guide the deposition of protamines into the DNA [1]. This induces a conformational change from a nucleosomal into a toroidal chromatin structure, with few remaining histone solenoid structures, thereby conferring DNA hypercondensation [2,3]. Chromatin remodeling is pivotal for sperm function as it is supposed to protect the paternal genome from environmental noxa, to induce a transcriptionally quiescent state and to contribute to the hydrodynamic shape of the sperm head [4].

Protamines are characterized by a high content of arginine- and cysteine-rich domains. While positively charged arginine residues mediate binding to the negatively charged DNA, alternating cysteine residues mediate the formation of intra- and intermolecular disulfide bridges, thereby strengthening DNA compaction $[5,6]$. In humans and many rodents two protamines, Protamine- 1 (Prm1) and Protamine-2 (Prm2) are expressed in species-specific ratios [7]. Aberrations of the ratio have been correlated with subfertility in men in many studies [8-16]. Apart from defects in DNA hypercondensation, impaired protamination was additionally correlated with increased DNA damage, reduced sperm motility, decreased viability and acrosomal malformations [17-22]. In consequence, infertile men with irregular protamination show decreased fertilization rates in ART (Assisted Reproductive Technologies) programs [23-25].

Since cell culture models for human spermatogenesis are scarce and inefficient, mouse models have contributed to a broader understanding of protamine function. Several knockout studies for both, Prm1 as well as Prm2, have shown that both isoforms are indispensable for male fertility in mice as well [26-29]. Similar to human sperm, impaired protamination was linked to faulty DNA compaction and increased DNA fragmentation. Further, sperm displayed secondary defects like a decline in motility and morphological abnormalities.

In this study, we used a Prm2-deficient mouse model established by us to study the molecular origin of these defects using sperm proteomics.

\section{Materials and Methods}

\subsection{Animals}

All animal experiments were conducted according to German law of animal protection and in agreement with the approval of the local institutional animal care committees (Landesamt für Natur, Umwelt und Verbraucherschutz, North Rhine-Westphalia, Germany, approval ID: AZ84-02.04.2013.A429, approved: 13.02.2014). Prm2-deficient mice (MGI: 5760133; 5770554) were generated and characterized as published previously [29].

\subsection{Protein Isolation from Tissue}

Fresh tissue samples were taken up in RIPA buffer (Cell Signaling Technology, Cambridge, UK) supplemented with protease inhibitor cocktail (cOmplete ${ }^{\mathrm{TM}}$ ULTRA, Roche, Basel, Switzerland) and minced in a glass dounce homogenizer. Samples were sonicated (Bioruptor, Diagenode, Seraing, Belgium) for $5 \mathrm{~min}$ at $30 \mathrm{~s}$ intervals after incubation on ice for $15 \mathrm{~min}$. Cell debris was removed by centrifugation $\left(20,800 \times g, 30 \mathrm{~min}, 4^{\circ} \mathrm{C}\right)$. Protein concentrations were quantified using the Pierce ${ }^{\mathrm{TM}} \mathrm{BCA}$ Protein Assay Kit (Thermo Fisher Scientific, Waltham, MA, USA).

\subsection{Protein Isolation from Sperm}

Isolated sperm were washed once with PBS containing protease inhibitors and pelleted by centrifugation ( $800 \mathrm{~g}, 7 \mathrm{~min}, \mathrm{RT}$ ). Next, sperm were dissolved in $\mathrm{H}_{2} \mathrm{O}$ supplemented with protease inhibitors to induce lysis of contaminating non-sperm cells (e.g., blood cells) by hypotonic shock. Sperm pellets were dissolved in RIPA buffer (Cell Signaling Technology, $10 \mu \mathrm{L}$ per $1 \times 10^{6}$ sperm) supplemented with protease inhibitor cocktail and $100 \mathrm{mM}$ DTT. Following incubation on ice for 30 
min, samples were sonified for $5 \mathrm{~min}$ in $30 \mathrm{~s}$ intervals using a Bioruptor sonication device (Diagenode, Seraing, Belgium). Samples were diluted in Roti ${ }^{\circledR}$-Load 1 and boiled at $95^{\circ} \mathrm{C}$ for $5 \mathrm{~min}$. Cell debris was removed by centrifugation $\left(20,800 \times g, 4^{\circ} \mathrm{C}\right)$. Protein concentrations were quantified using the Pierce $660 \mathrm{~nm}$ Protein Assay Reagent supplemented with Ionic Detergent Compatibility Reagent according to the 96-well microplate procedure of the manufacturer's protocol assay (Thermo Fisher Scientific).

\subsection{Immunoblotting}

Protein lysates were separated on $12 \%$ SDS polyacrylamide gels and transferred to PVDF membranes using the Trans-Blot Turbo System (BioRad, Feldkirchen, Germany). Equal protein loading and successful blotting was verified by Coomassie Brilliant Blue staining. Membranes were blocked in 5\% non-fat dry milk powder in phosphate buffered saline with 1\% Tween20 (PBS-T) for $1.5 \mathrm{~h}$ at room temperature. Primary and secondary antibodies were diluted in blocking solution as specified in Table 1 and incubated at $4^{\circ} \mathrm{C}$ overnight and $1 \mathrm{~h}$ at room temperature, respectively. Following incubation with Pierce Super Signal West Pico chemiluminescent substrate (Perbio, Bonn, Germany), chemiluminescent signals were detected with ChemiDocMP Imaging system (BioRad).

Table 1. Antibodies and dilutions used in this study.

\begin{tabular}{llll}
\hline \multicolumn{1}{c}{ Antibody } & \multicolumn{1}{c}{ Company } & \multicolumn{1}{c}{ Product-No. } & \multicolumn{1}{c}{ Dilution (IB) } \\
\hline SOD1 & Abcam, Cambridge, UK & ab16831 & $1: 1000$ \\
PRDX5 & Abcam, Cambridge, UK & ab231892 & $1: 500$ \\
$\alpha$-tubulin & Santa Cruz Biotechnology, Dallas, TX, USA & sc-8035 & $1: 500$ \\
$\beta$-actin & Sigma, St. Louis, MO, USA & A5441 & $1: 10000$ \\
anti-mouse HRP & Dako, Glostrup, Denmark & P0260 & $1: 1000$ \\
anti-rabbit HRP & Dako, Glostrup, Denmark & P0448 & $1: 2000$ \\
\hline
\end{tabular}

\subsection{Mass Spectrometry}

Following separation of protein extracts by SDS-PAGE, protein gels were shortly washed with $\mathrm{dd}_{2} \mathrm{H}_{2} \mathrm{O}$ and stained with colloidal Coomassie overnight at RT. Gels were washed twice with $1 \%(v / v)$ acetate in $\mathrm{dd}_{2} \mathrm{H}_{2} \mathrm{O}$ and protein lanes were cut into 12 fractions according to their molecular weight. Each fraction was further chopped into squares of around $1 \mathrm{~mm}^{2}$, transferred to protein low-binding tubes and fixed with $150 \mu 150 \%(v / v) \mathrm{MeOH}$. The fixation solution was replaced by $150 \mu \mathrm{L}$ destaining solution, followed by incubation for $20 \mathrm{~min}$ at $37^{\circ} \mathrm{C}$ under vigorous shaking. The destaining step was repeated $2-3 \times$ until gel pieces appeared clear and gel slices were dried in a vacuum centrifuge. In-gel digestion of proteins was performed with trypsin solution followed by separation of peptides by liquid chromatography (LC) in a gradient using HSS-T3 analytical columns (1.8 $\mu \mathrm{m}$ particle, $75 \mu \mathrm{m} \times$ $150 \mathrm{~mm}$ ) in combination with the nanoAcquity LC pump system. Peptides were analyzed on a LTQ Orbitrap Elite mass spectrometer (Thermo Fisher) as described [30] and raw data were processed with Proteome Discoverer software version 2.3.0.523 (Thermo Fisher).

Peptide identification was done with an in-house Mascot server version 2.6.1 (Matrix Science Ltd., London, UK). MS data were searched against the mouse reference proteome from Uniprot (2019/05) and a contaminants database (cRAP) [31]. Precursor ion $\mathrm{m} / \mathrm{z}$ tolerance was $10 \mathrm{ppm}$, fragment ion tolerance $0.5 \mathrm{Da}$. Tryptic peptides with up to two missed cleavage were searched. Propionamidylation of cysteines was set as static modification. Oxidation (Met) and acetylation (protein N-termini) were allowed as dynamic modification. Mascot results were evaluated by the Percolator algorithm [32] version 3.02.1 as implemented in Proteome Discoverer. Spectra with identifications above q-value 0.01 were sent to a second round of database search with semi-tryptic enzyme specificity (one missed cleavage allowed). Propionamide and carbamidomethyl were set as additional dynamic cysteine modification. 362,449 peptide spectrum matches (PSMs) were identified with high confidence out of $1,789,702$ spectra. 26,084 peptide groups of 7,432 proteins were included. These were assigned to 3,046 distinguishable protein groups. 2,591,992 features were considered for quantification. Actual FDR values of the whole dataset were $0.4 \%, 1.0 \%$, and $7.3 \%$ for PSMs, peptides, and proteins, respectively. 
The mass spectrometry proteomics data have been deposited to the ProteomeXchange Consortium via the PRIDE [33] partner repository with the dataset identifier PXD018843 and 10.6019/PXD018843.

Protein quantification and statistical evaluation were performed in $\mathrm{R}$ environment (version 3.5.2 [34] on the PSM level data, exported from Protein Discoverer. First, low quality data, including ambiguous peptides matching to more than one protein and proteins detected by a single peptide only were removed from the dataset. Next, the data were variance-stabilized and transformed using Variance Stabilizing Normalization (VSN) [35]. Protein abundances were calculated for each replicate by summarizing measurements of all peptides linked to the respective protein using Tukey's median polish procedure. To decipher the overall structure within the dataset, PCA analysis was performed using the R-package FactoMineR [36]. For statistical analyses, comparative analyses between different sample groups were performed using moderated t-test from the R-package Limma (version 3.40.2) [37]. The resulting p-values were adjusted for multiple testing using the Benjamini-Hochberg method. Proteins with a false discovery rate (FDR) smaller than 0.05 and an absolute fold-change greater than 1 were considered to be significantly differentially regulated. Plots and heatmaps were generated utilizing the published R-packages ggplot2 and Complex heatmaps [38,39].

\subsection{Immunohistochemistry}

Dissected tissues were fixed in Bouin's solution at $4^{\circ} \mathrm{C}$ overnight and processed in paraffin wax. Sections of $3 \mu \mathrm{m}$ thickness were obtained on glass slides, deparaffinized, rehydrated and treated with decondensing buffer (25 mM DTT, 0.2\% (v/v) Triton x-100 and 200 i.U./mL heparin in PBS) for $1 \mathrm{~min}$ at $37^{\circ} \mathrm{C}$ to increase antigen accessibility. Sections were further processed in the Lab Vision PT module (Thermo Fisher Scientific) and Autostainer 480S (Medac, Hamburg, Germany) as published previously [40]. The primary antibody against 8-OHdG (clone 15A3, Santa Cruz Biotechnology, Dallas, TX, USA) was used at a dilution of 1:200.

\subsection{Enzyme-Linked Immunosorbent Assay (ELISA)}

8-OHdG levels were quantified in DNA of epididymal sperm, which was isolated by phenol/chloroform extraction as published elsewhere [41]. ELISA was performed according to the manufacturer's instructions of the Oxiselect ${ }^{\mathrm{TM}}$ Oxidative DNA Damage ELISA Kit (STA-320, Cell Biolabs Inc., Cologne, Germany), including pretreatment of DNA with Nuclease P1 (N8630, Sigma-Aldrich/Merck, Darmstadt, Germany) and alkaline phosphatase (Sigma-Aldrich/Merck). $3 \mu \mathrm{g}$ of DNA were used as input. The primary antibody (8-OHdG) was used at a dilution of 1:500 and the secondary antibody at a dilution of 1:1000. Absorbance was recorded at $450 \mathrm{~nm}$ (Multiskan GO 1510, Thermo Fisher) and interpreted with Curve Expert 1.4 (Hyams Development, www.curveexpert.net). Statistical analysis was performed with GraphPad Prism 8 (GraphPad Software, San Diego, CA, USA).

\subsection{Sperm Vitality Assessment}

Sperm vitality was analyzed by eosin-nigrosin staining and hypoosmotic swelling test as published elsewhere [42].

\subsection{Periodic Acid Schiff Staining (PAS)}

Bouin's fixed testicular tissue sections were deparaffinized, re-hydrated and incubated with periodic acid $\left(0.5 \%\right.$ in $\left.\mathrm{H}_{2} \mathrm{O}\right)$ for $10 \mathrm{~min}$. Slides were rinsed with $\mathrm{H}_{2} \mathrm{O}$ and treated with Schiff reagent for 20 min. Finally, slides were washed with $\mathrm{H}_{2} \mathrm{O}$ for $7 \mathrm{~min}$, counterstained with Haemalaun, dehydrated and mounted with a coverslip.

\subsection{Sperm Nuclear Morphology Analysis}

For testicular sperm, $5 \mu \mathrm{m}$ thick testicular cross sections were stained with Mayer's Haemalum solution (Merck) and mounted with Dako Faramount Aqueous Mounting Medium (Dako, Carpinteria, 
CA, USA). Digital photographs of elongating and elongated spermatids were taken at 400x magnification. Spermatid length and width were determined using a macro written for ImageJ, which can be made available upon request.

Epididymal sperm were analyzed using the ImageJ plugin "Nuclear morphology analysis v1.14.1" according to the developers instructions [43]. Briefly, isolated sperm were pelleted by centrifugation $(500 \mathrm{~g}, 5 \mathrm{~min}, \mathrm{RT})$ and fixed by dropwise addition of methanol:acetic acid $(3: 1,(v / v))$. Samples were washed three times with fixative, spread on glass slides, air-dried and mounted with ROTI ${ }^{\circledR}$ Mount FluorCare DAPI (Carl Roth, Karlsruhe, Germany). Sperm heads were imaged under oil immersion at 100-fold magnification using an epifluorescence microscope (DM5500B, Leica, Wetzlar, Germany) equipped with a 3CCD-camera (KY-F75U, JVC, Yokohama, Japan). At least 140 sperm heads from three biological replicates each were included into the analysis.

\subsection{RNAseq Analysis}

Total RNA was extracted from testicular tissue after removal of the tunica albuginea using TRIzol ${ }^{\mathrm{TM}}$ reagent according to the manufacturer's protocol (Thermo Fisher Scientific). RNA integrity (RIN) was determined using the RNA Nano 6000 Assay Kit with the Agilent Bioanalyzer 2100 system (Agilent Technologies, Santa Clara, CA, USA). RIN values ranged from 8.2-10 for all samples. RNA sample quality control and library preparation were performed by the University of Bonn Core facility for Next Generation Sequencing (NGS), using the QuantSeq 3'-mRNA Library Prep (Lexogen, Greenland, $\mathrm{NH}, \mathrm{USA}$ ). RNAseq was performed on the Illumina HiSeq $2500 \mathrm{~V} 4$ platform, producing $>10$ million, $50 \mathrm{bp} 3^{\prime}$-end reads per sample.

All reads were mapped to the mouse genome (GRCm38.89) using HISAT2 2.1 [44]. Transcripts were quantified and annotated using StringTie 1.3.3 [45]. Gene annotation information for the mouse genome was retrieved from the Ensembl FTP server (ftp://ftp.ensembl.org) (GRCm38.89). The python script (preDE.py) included in the StringTie package was used to prepare gene-level count matrices for analysis of differential gene expression (DE).

DE was tested with DESeq2 1.16.1 [46]. Pseudogenes were removed from the count matrices based on "biotype" annotation information extracted from Biomart (R-package biomaRt, [47]). Low counts were removed by the independent filtering process, implemented in DESeq2 [48]. The adjusted p-value (Benjamini-Hochberg method) cutoff for DE was set at $<0.05, \log _{2}$ fold change of expression (LFC) cutoff was set at $>0.5$.

We performed GO term and pathway overrepresentation analyses on relevant lists of genes from $\mathrm{DE}$ and co-expression analyses using the PANTHER gene list analysis tool with Fisher's exact test and FDR correction [49]. We tested for overrepresentation based on the GO annotation database (Biological Processes) (released 2 February 2019, [50]) and the Reactome pathway database (version 58 [51]). The RNAseq data discussed in this publication have been deposited in NCBI's Gene Expression Omnibus [52] and are accessible through GEO Series accession number GSE149454.

\subsection{Intracytoplasmatic Sperm Injection (ICSI)}

B6D2F1 females were superovulated by intraperitoneal injection of 5 i.U. Pregnant Mare Serum (PMS) and human Chorionic Gonadotropin (hCG). Oocytes were isolated from the oviducts $15 \mathrm{~h}$ after the last hormone injection and freed from cumulus cells by treatment with hyaluronidase. Testicular sperm were isolated from 8-13 week-old males as described [53]. Briefly, after removal of the tunica albuginea, testes were placed into 1\% ( $m / v)$ PVP solution (P5288, Sigma) and cut into minute pieces. One part of the testicular suspension was throughout mixed with two parts $12 \% \mathrm{PVP}$ solution and incubated at $16^{\circ} \mathrm{C}$ until injection.

ICSI was performed at $17^{\circ} \mathrm{C}$ using an inverted microscope (Leica, Wetzlar, Germany) equipped with micromanipulators (Narishige, Tokyo, Japan) and a piezo element (Eppendorf, Hamburg, Germany). Injection capillaries (PIEZO 8-15-NS, Origio, Charlottesville, VA, USA) were filled with Fluorinert (FC-770, Sigma) for proper Piezo pulse propagation. Testicular sperm were collected and 
injected into oocytes as described in detail by Yoshida et al. [54] with minor modifications. Here, testicular sperm were injected head to tail without prior removal of the sperm flagellum. Oocytes were cultured in M2 medium (Sigma) for injection. Surviving oocytes were cultivated in a drop-culture of $\mathrm{KSOM}$ (Gynemed, Lensahn, Germany) under mineral oil (Gynemed) at $37^{\circ} \mathrm{C}$ and $5 \% \mathrm{CO}_{2}$.

\subsection{Genotyping of Blastocysts}

DNA was extracted from blastocysts as published [55]. Briefly, single embryos were supplemented with $10 \mu \mathrm{L}$ embryo lysis buffer ( $50 \mathrm{mM} \mathrm{KCl}, 10 \mathrm{mM}$ Tris-HCl pH 8.3, $2.5 \mathrm{mM} \mathrm{MgCl}, 0.1 \mathrm{mg} / \mathrm{mL}$ gelatin, $0.45 \%(v / v) \mathrm{NP} 40,0.45 \%(v / v)$ Tween-20, $0.1 \mathrm{mg} / \mathrm{mL}$ proteinase $\mathrm{K})$ and incubated at $56{ }^{\circ} \mathrm{C}$ for 30 $\mathrm{min}$, followed by $95^{\circ} \mathrm{C}$ for $10 \mathrm{~min}$. Lysates were cooled down to RT and vortexed vigorously. Prm2 genotyping was conducted as published previously [29] using $5 \mu \mathrm{L}$ of the lysate as input.

\section{Results}

\subsection{To the Molecular Origin of Secondary Defects in Prm2-Deficient Sperm}

Previous attempts to establish Prm2-deficient mouse lines using classical gene-targeting failed as male chimeras generated by blastocyst injection of $\mathrm{Prm}^{+/-}$ES-cells were sterile [26]. This prohibited detailed functional studies on protamine function in mice. Recently, we reported the successful generation and establishment of Prm2-deficient mouse lines using CRISPR/Cas9-mediated gene-editing in oocytes [29]. Interestingly, $\mathrm{Prm}^{+/-}$males displayed normal fecundity with sperm being morphologically and functionally indistinguishable from wildtype sperm. This enabled the breeding of $\mathrm{Prm}^{-/-}$males, which are infertile. Comprehensive phenotypical characterization revealed that the loss of Prm 2 did neither affect the efficiency of spermatogenesis nor epididymal sperm counts but resulted in defective DNA integrity in more than $90 \%$ of sperm [29]. Furthermore, $100 \%$ of sperm were immotile, displayed morphological malformations, membrane defects and a decline in viability [29] (Supplementary Figure S1). We categorized the latter as secondary defects, as they cannot be explained by the molecular function of protamines. Since incorporation of protamines into the sperm DNA is supposed to induce transcriptional silencing, we expected to find the underlying reason for induced secondary sperm defects rather on proteomic than on transcriptomic level. Therefore, epididymal sperm protein lysates from wildtype, $\mathrm{Prm}^{+/-}$and $\mathrm{Prm}^{-/-}$males were pre-fractionated by SDS gel electrophoresis and subjected to LC-MS (liquid chromatography-mass spectrometry). In total, 3.318 different proteins were identified with high confidence. Following removal of non-unique peptides and single-shot proteins, 2.299 proteins were considered for label-free quantification (Figure S2A,B). In order to evaluate the power of the generated dataset, we compared the list of identified proteins with the compiled murine sperm proteome of four previous studies [56-59] showing a coverage of $63 \%$ (Figure 1A).

Our analysis detected 1,498 additional proteins, which had not been identified previously. Further, we also compared our dataset with the human sperm proteome, which has been studied in much more detail [60]. Of note, $77 \%$ of the murine sperm proteome were overlapping with the human sperm proteome (Figure 1A). Thus, we concluded that the present dataset reflects a significant portion of the murine sperm proteome. Following data normalization and quality controls (Supplementary Figures S2C,D), a principle component analysis was performed. Knockout replicates clustered strongly apart from controls, being indicative for an overall biological difference (Figure 1B). This was verified by heatmap visualization of the most significantly deregulated proteins. Knockout replicates displayed a strongly altered proteomic profile and were only distantly related to control replicates as visualized by hierarchical clustering using the Euclidian distance (Figure 1C). In accordance with the phenotypical characterization, a highly similar proteomic profile was observed for wildtype and $\mathrm{Prm}^{+/-}$replicates. 
A

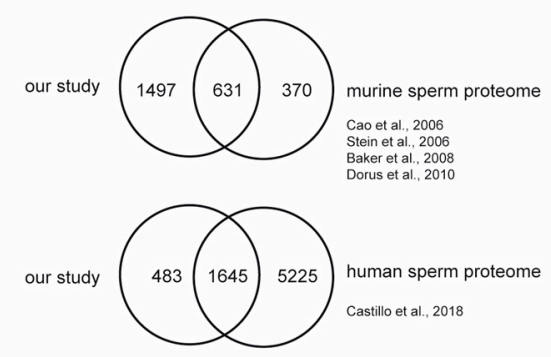

B

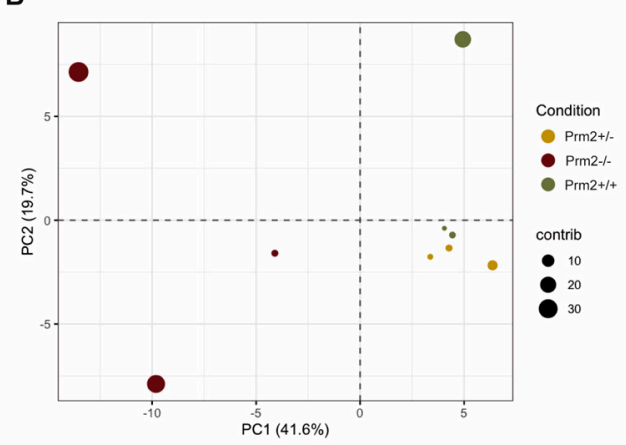

C

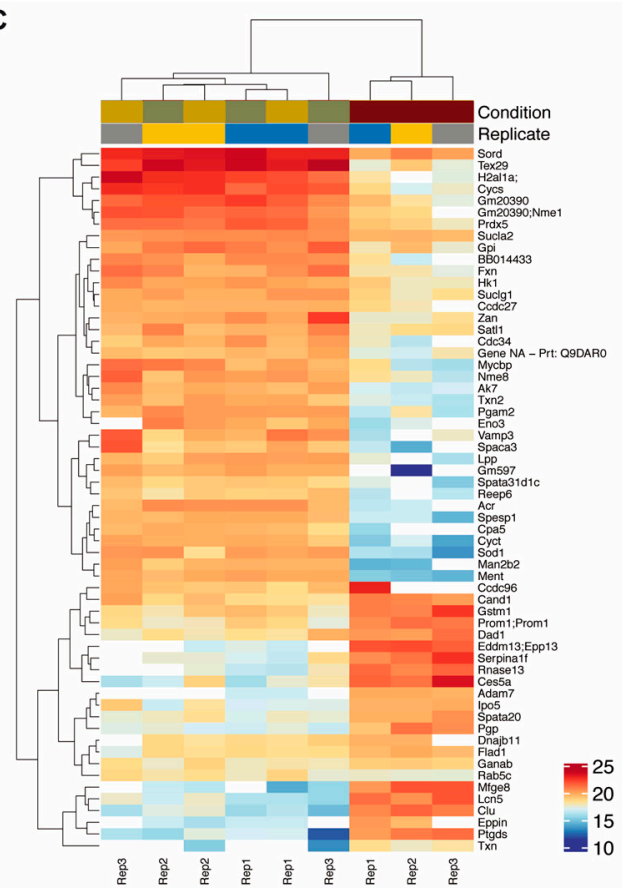

Figure 1. The sperm proteome of Prm2-deficient mice. (A) Venn diagrams showing the overlap of the generated dataset with published datasets of murine and human sperm. (B) Principal component analysis (PCA). MS comprised three biological replicates per genotype. Contribution of each dataset to the PCA is reflected by the dot size. (C) Heatmap visualization of the top 50 most significantly deregulated proteins $\left(\mid \log _{2} \mathrm{FCl}>1\right.$; FDR $\left.<0.05\right)$ between Prm $2^{+/+}$, Prm $^{+/-}$and $P r m 2^{-/-}$samples.

No proteins were found to be significantly up- or downregulated (Figure 2A). However, in the knockout condition, 24 proteins were found to be significantly deregulated compared to wildtype (17 down- and 8 upregulated) (Figure 2A). A highly similar set of deregulated proteins was observed by pairwise comparison of knockout and heterozygous samples (Figure 2A). Many of the differentially expressed proteins, including SORD, SOD1, PRDX5 and ACR have a well-known function for male fertility and sperm motility [61-64]. Thus, deregulated proteins correlate with the observed defects. To investigate whether deregulations can be attributed to specific biological processes, reactome pathway analysis was performed, showing a significant enrichment of downregulated proteins in processes of energy metabolism and the detoxification of ROS (Figure 2B). Further, STRING analysis suggests a strong interaction among the downregulated proteins (Figure 2C). Taken together, MS data imply that loss of PRM2 triggers a molecular cascade that initiates described secondary sperm defects, which ultimately result in male infertility.

A

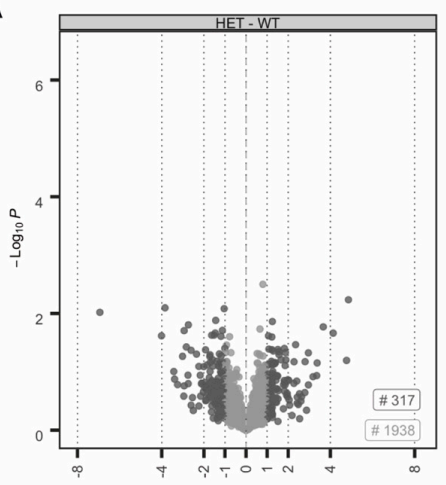

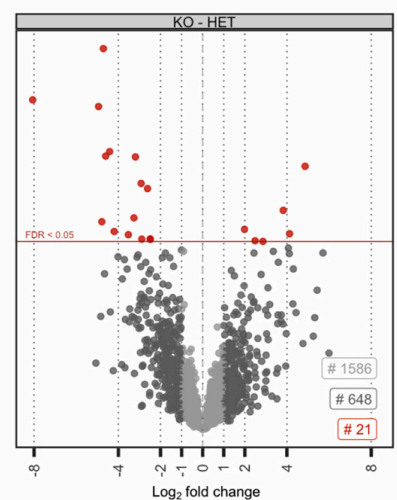

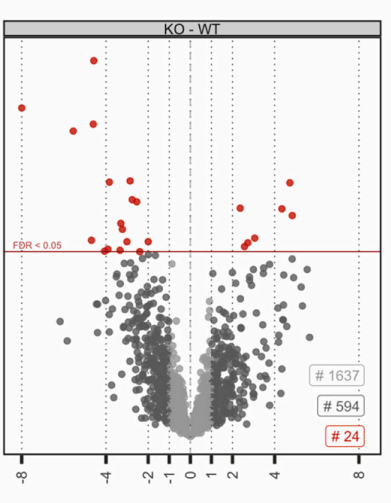

Figure 2. Cont. 
B

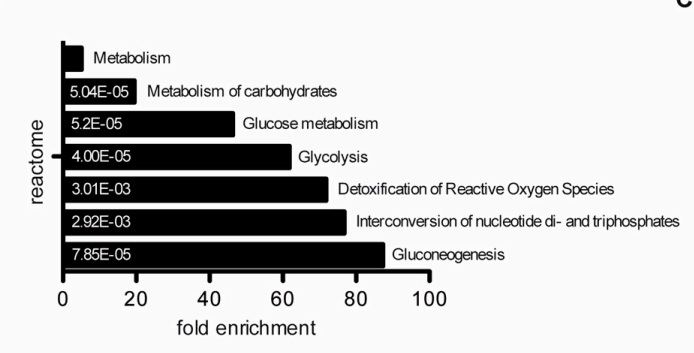

C

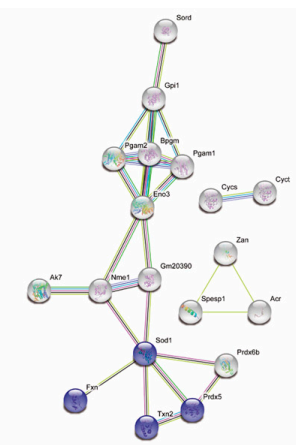

Figure 2. The molecular function of deregulated proteins in Prm2-deficient sperm. (A) Volcano plots displaying DE proteins in pairwise comparison of $\mathrm{Prm}^{+/+}$(WT), Prm2 ${ }^{+/-}$(HET) and Prm2 $2^{-/-}$(KO) samples. (B) Reactome pathway analysis of proteins downregulated in $\mathrm{Prm} 2^{--}$sperm compared to wildtype $\left(\left|\log _{2} \mathrm{FC}\right|>1\right.$; FDR $\left.<0.1\right)$. FDR is given in each bar. (C) STRING analysis of proteins downregulated in $\mathrm{Prm}^{-/}$sperm compared to wildtype $\left(\left|\log _{2} \mathrm{FC}\right|>1 ; \mathrm{FDR}<0.1\right)$. Proteins involved in biological processes of hydrogen peroxide metabolism are highlighted in blue.

\subsection{Prm2 Deficiency Induces a Downregulation of ROS Scavenger Proteins}

Since excessive levels of reactive oxygen species (ROS) are well-known mediators of cellular damage, including DNA damage and lipid peroxidation, the potential role of imbalanced ROS level was investigated in detail. Among the differentially expressed proteins, superoxide dismutase 1 (SOD1) and peroxiredoxin 5 (PRDX5) were identified as key players of ROS detoxification. SOD1 catalyzes the conversion of superoxide radicals into hydrogen peroxide, which is subsequently degraded into non-toxic $\mathrm{H}_{2} \mathrm{O}$ molecules. PRDX5 is another cytoprotective antioxidant enzyme that catalyzes the reduction of hydrogen peroxide, alkyl hydroperoxide and peroxynitrite [65]. Thus, both enzymes have ROS scavenging function that might result in oxidative stress upon loss. As shown in the profile plots for SOD1 and PRDX5, the relative abundance of SOD1 and PRDX5 peptides identified by MS was strongly diminished in Prm2 $2^{-/-}$sperm compared to controls (Figure 3A and Supplementary Figure S3).

To validate MS results independently, protein level of SOD1 and PRDX5 were determined by Western Blot analysis. Both, levels of SOD1 and PRDX5 were strongly decreased in Prm2 ${ }^{-1-}$ sperm compared to wildtype and $\mathrm{Prm}^{+/-}$samples (Figure 3B). However, in testicular lysates protein levels were not changed (Figure 3B). This suggests that the proposed ROS signaling cascade is first initiated during epididymal transit. 
A

SOD1

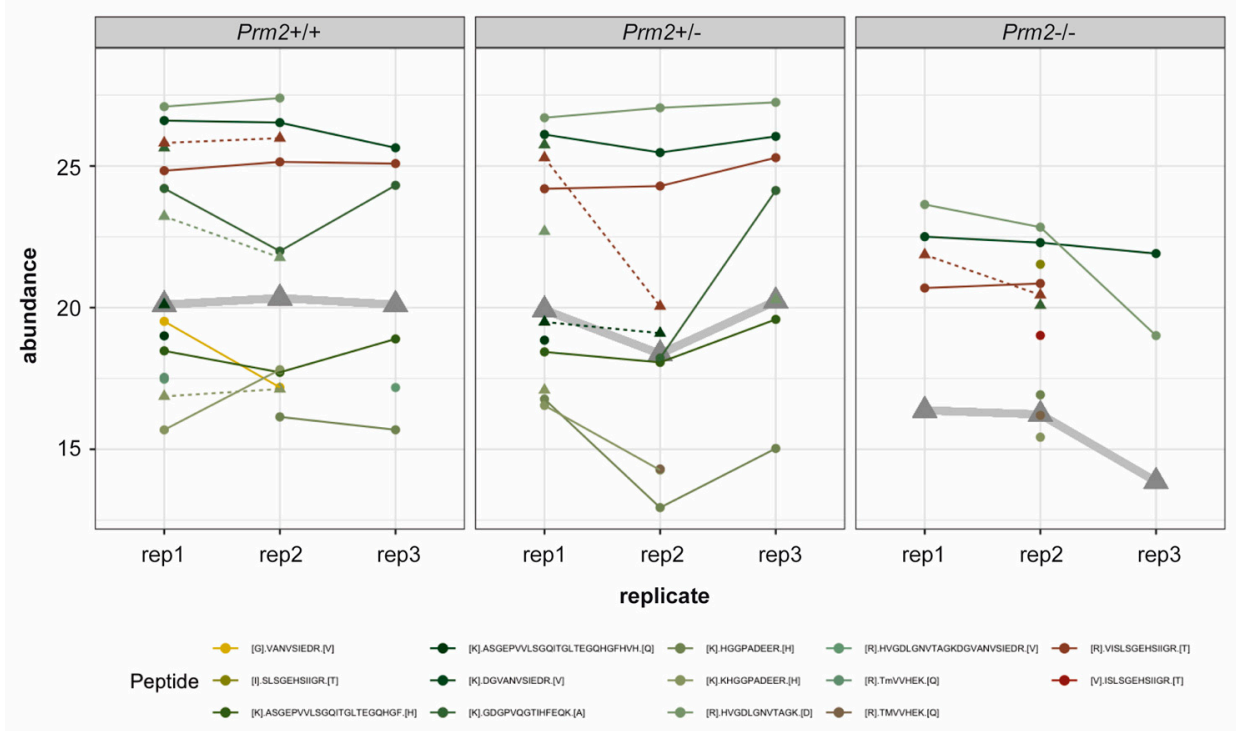

B

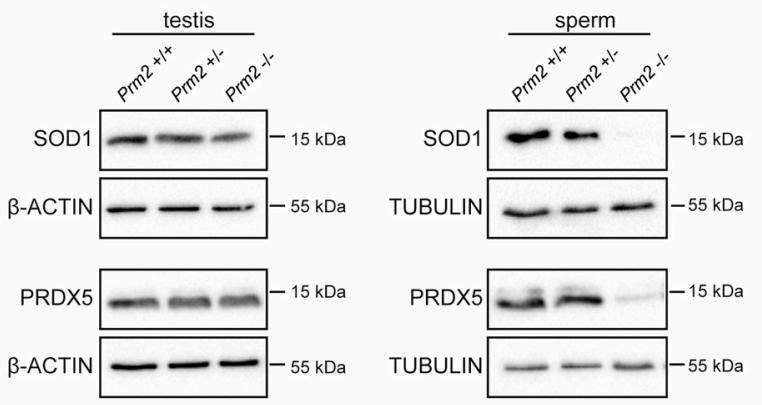

Figure 3. ROS scavenger proteins SOD1 and PRDX5 are downregulated in Prm2-deficient sperm. (A) Profile plots showing the relative abundance of identified SOD1 peptides within each replicate of $\mathrm{Prm}^{+/+}, \mathrm{Prm}^{+/-}$and Prm $^{-/-}$sperm. The protein abundance calculated by Tukey's median polish is resembled by thickened grey lines. (B) Representative immunoblot against SOD1 and PRDX5 on protein lysates from $\mathrm{Prm}^{+/+}, \mathrm{Prm}^{+/-}$and $\mathrm{Prm}^{-/-}$testes and epididymal sperm $(n=1-3)$. Beta-actin and tubulin served as loading control.

\subsection{Oxidative Stress Causes DNA Damage During Epididymal Sperm Maturation}

To prove the hypothesis that excessive ROS levels are the cause of secondary sperm defects, testicular and epididymal tissue sections were stained against 8-OHdG (8-hydroxy-2'-deoxyguanosine, 8-hydroxyguanine and 8-hydroxyguanosine). Of note, mature step 16 spermatids of all genotypes stained negative for 8-OHdG, indicative for intact and undamaged DNA (Figure 4A). 


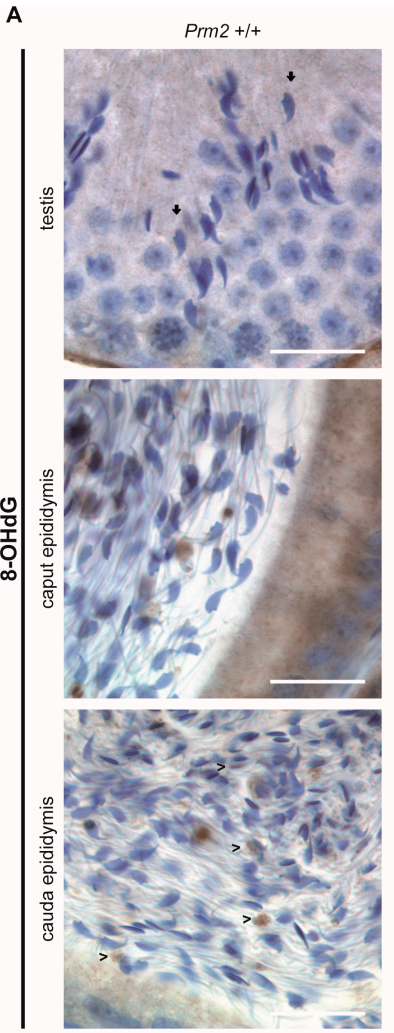

A

B

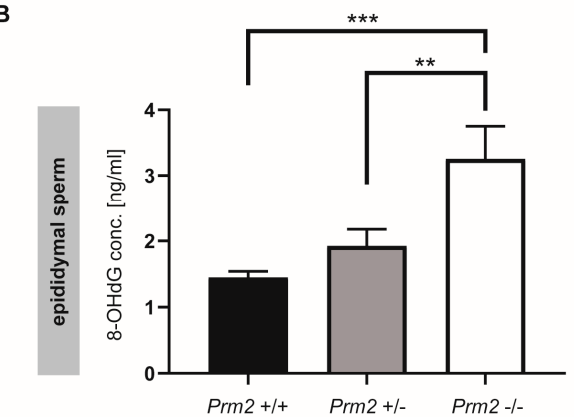

Prm2 +/+ Prm2+/- Prm2 -/
$\operatorname{Prm} 2+/-$
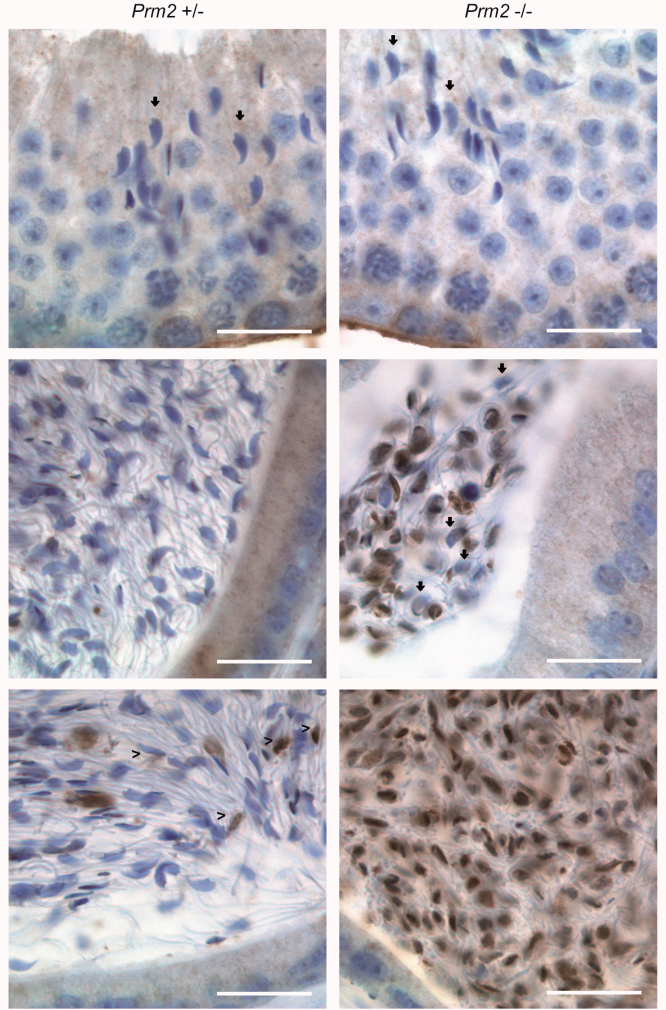

Figure 4. Oxidative stress causes DNA damage in Prm2-deficient sperm during epididymal maturation. (A) Representative immunohistochemical staining $(n=3)$ against 8 -OHdG as a biomarker for oxidative DNA damage. Staining of testicular (top row), caput epididymal (middle row) and cauda epididymal (bottom row) tissue sections from $\mathrm{Prm}^{+/+}$(left column), $\mathrm{Prm}^{+/-}$(middle column) and Prm2 ${ }^{-/}$(right column) animals is shown. Note increasing oxidative damage in Prm2-deficient sperm during epididymal transit. Arrows highlight 8-OHdG negative spermatids/sperm, arrowheads 8-OHdG positive cells. Scale bar: $20 \mu \mathrm{m}$. (B) Quantification of 8-OHdG levels in epididymal sperm DNA from Prm $^{+/+}$, Prm $^{+/-}$and Prm2 ${ }^{-/-}$males by ELISA ( $\mathrm{n}=5$; statistical significance was determined by non-parametric Kruskal-Wallis-Test, $\left.{ }^{* *} p=0.0002 ;{ }^{* * *} p<0.0001\right)$.

However, in Prm2 ${ }^{-/-}$males, increasing levels of 8-OHdG positive sperm nuclei were identified during epididymal transit. After release from the testis, sperm first pass through the corpus and caput epididymis. At this stage, 8-OHdG positive nuclei were first detected. Some nuclei were completely stained while others showed a more granular staining (Figure 4A). Still, some sperm nuclei stained negative for 8-OHdG (Figure 4A, arrowheads). With proceeding sperm maturation signals intensified. In tissue sections of the cauda epididymis, almost all sperm nuclei showed a strong staining for 8-OHdG, being highly suggestive for oxidative stress-mediated DNA damage. In contrast, sections of caput and cauda epididymis from $\mathrm{Prm}^{+/+}$and $\mathrm{Prm} 2^{+/-}$displayed only few 8-OHdG positive cells (Figure 4A, arrows). To quantify the increase in oxidative DNA damage in Prm2-/- epididymal sperm, 
an enzyme-linked immunosorbent assay (ELISA) was performed. The concentration of 8-OHdG was highly significantly increased from $1.449 \mathrm{ng} / \mathrm{mL}$ in DNA from wildtype sperm to $3.256 \mathrm{ng} / \mathrm{mL}$ in $\mathrm{Prm}^{-/-}$sperm (Figure 4B). Only a slight, but non-significant increase in 8-OHdG concentrations was observed between wildtype and $\mathrm{Prm}^{+/-}$sperm. Taken together, the results clearly show that Prm2 deficiency leads to an imbalance in the ROS scavenging system, supposedly leading to elevated ROS levels triggering a reactive oxygen-mediated destruction cascade in sperm, which is exerted during epididymal sperm maturation.

\subsection{Secondary Sperm Defects Arise During Epididymal Maturation}

To verify that other secondary sperm defects can be also assigned to the proposed ROS pathway, these defects are expected to appear and intensify during epididymal sperm maturation as well. The initial phenotypical characterization showed severe acrosomal malformations in Prm2-deficient cauda epididymal sperm [29]. Here, periodic-acid-Schiff (PAS) staining, which stains glycoprotein-rich acrosomal structures pink, was performed on testicular tissue sections. Acrosomal vesicles were first detected in round spermatids (Figure 5A, arrowheads).

In the course of spermiogenesis, vesicles elongated and finally capped the sickle-shaped head of step 16 spermatids of all genotypes (Figure 5A, arrows). This indicates that acrosome biogenesis is not impaired upon loss of $\operatorname{Prm} 2$ and that defects are inevitably acquired during epididymal transit.

Further, we analyzed the effects of Prm2 deficiency on the nuclear morphology of spermatids and mature sperm. The characteristic sickle-shaped nuclear morphology was observed in hematoxylin stained stage VII/VIII seminiferous tubules of all genotypes (Figure 5B). Quantification of nuclear head length and width revealed no significant differences between Prm2-deficient step 16 testicular spermatids and controls (Figure 5B), thus indicating that Prm2 is dispensable for proper shaping of the sperm head during spermiogenesis. However, severe changes in sperm nuclear morphology were observed in DAPI stained cauda epididymal sperm (Figure 5C). In general, most Prm2-deficient sperm nuclei appeared smaller in size and displayed loss of the characteristic sickle-shape compared to controls (Figure 5C). 
A
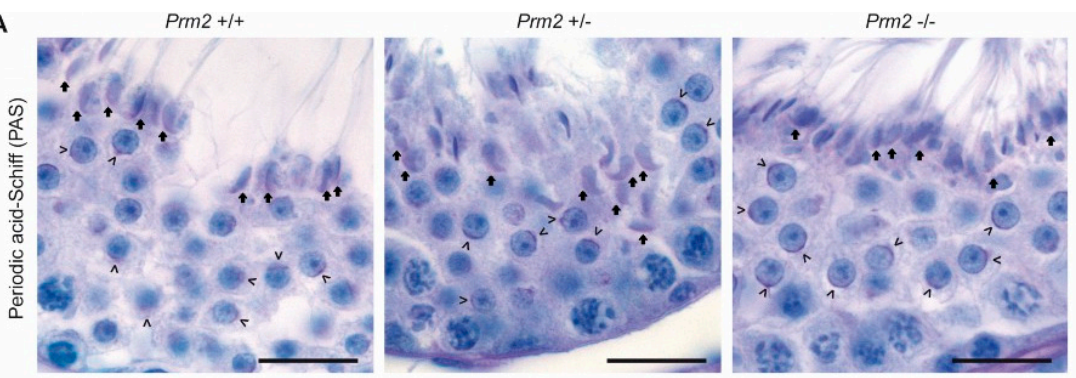

B
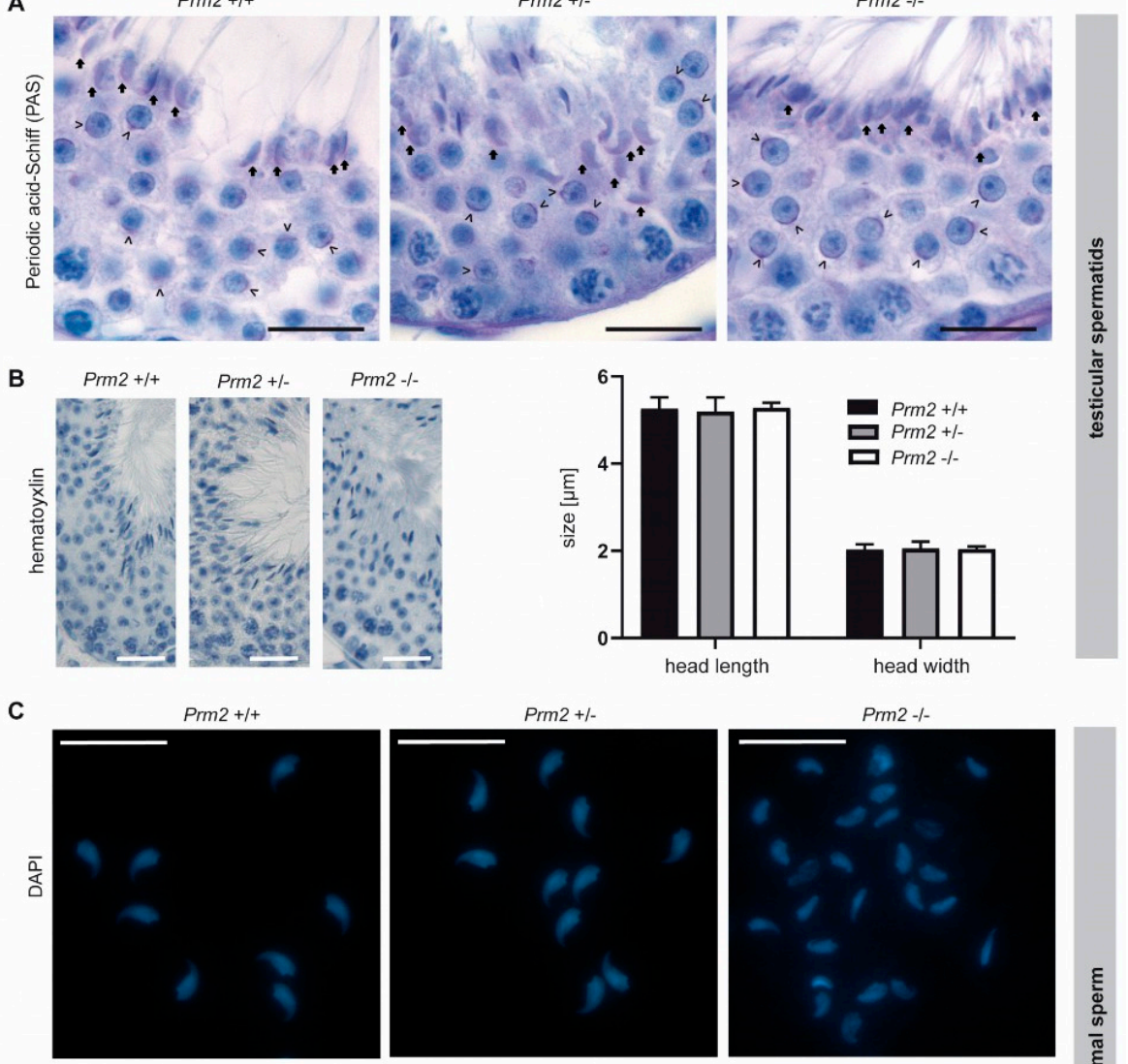

D
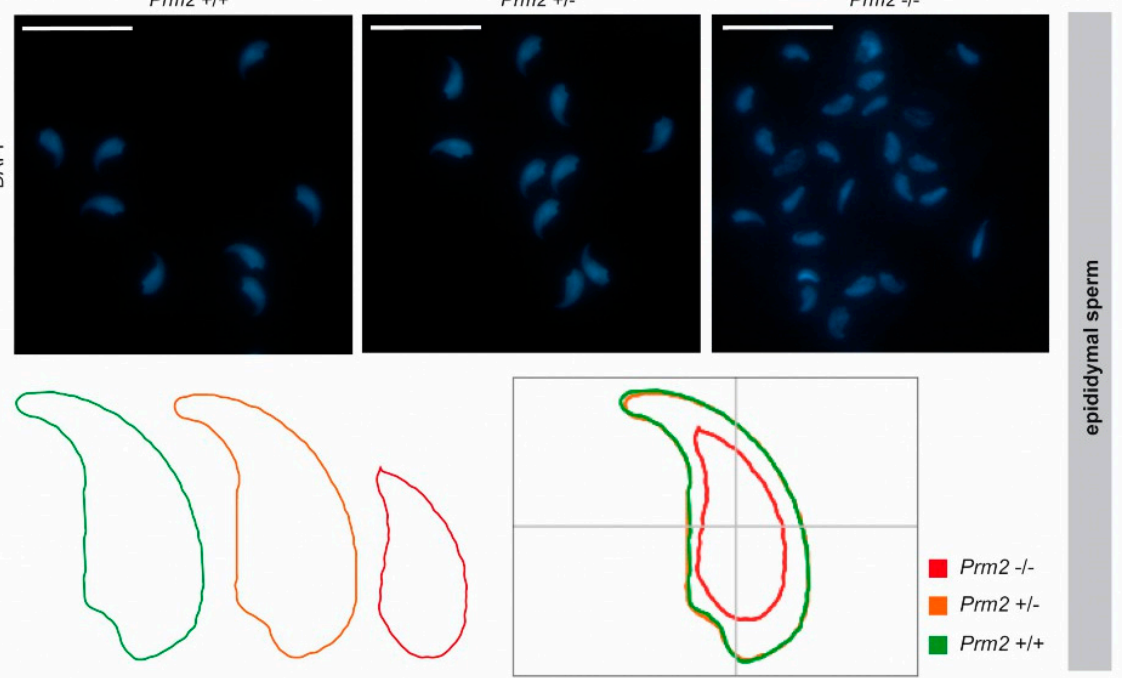

Figure 5. Secondary sperm defects are acquired during epididymal transit. (A) Periodic-acid-Schiff (PAS) staining of testicular tissue sections from $\mathrm{Prm}^{+/+}, \mathrm{Prm}^{+/-}$and $\mathrm{Prm}^{-/-}$males. Representative photomicrographs of stage VI/VII seminiferous tubules are shown. Proacrosomal vesicles of round spermatids are highlighted by arrowheads; mature acrosomes of step 16 spermatids by arrows. Scale bar: $20 \mu \mathrm{m}$. (B) Representative images of hematoxylin stained testicular step 16 spermatids. Scale bar: $25 \mu \mathrm{m}$. Quantification of sperm head length and width. Bars represent mean values $\pm \operatorname{SD}(n=5)$. (C) Representative images of DAPI-stained epididymal sperm from $\mathrm{Prm}^{+/+}, \mathrm{Prm}^{+/-}$and $\mathrm{Prm} 2^{-/-}$males. Scale bar: $20 \mu \mathrm{m}$. (D) Consensus shape computed for $\mathrm{Prm}^{+/+}$(green), $\mathrm{Prm}^{+/-}$(orange) and Prm2 $2^{-/-}$ (red) sperm populations.

However, morphological changes were variable, resulting in a highly heterogeneous sperm population (Figure 5C). To quantify changes in sperm nuclear head morphology, an automated, high-throughput analysis was performed. A consensus shape was computed for each genotype, visualizing the observed morphological changes (Figure 5D). With a median of $10.53 \mu \mathrm{m}^{2}$ (95\% confidence interval (CI) 10.96 $\left.\mu \mathrm{m}^{2} \pm 0.26\right)$, the head size of Prm2-deficient sperm was more than $40 \%$ reduced compared to controls with a median of $18.42 \mu \mathrm{m}^{2}\left(95 \%\right.$ CI $\left.18.38 \mu \mathrm{m}^{2} \pm 0.1\right)$ (Supplementary Figure S4). In line, the median sperm perimeter decreased from $21.13 \mu \mathrm{m}(95 \%$ CI $21.09 \mu \mathrm{m} \pm 0.08)$ to $14.21 \mu \mathrm{m}(95 \%$ CI $14.76 \mu \mathrm{m} \pm 0.25)$ (Supplementary Figure S4). Both, a decline of sperm length and width resulted in a decrease of sperm area and perimeter. Further, loss of the characteristic sperm hook caused an increase in circularity and ellipticity of Prm2-deficient sperm compared to controls (Supplementary Figure S4). 
Taken together, our analyses clearly demonstrate that the functional and morphological sperm defects observed are almost exclusively acquired during epididymal sperm maturation and correlate with the initiation of the postulated ROS cascade.

To assess whether Prm 2 deficiency affects global testicular gene expression, RNAseq analysis was performed on testicular RNA isolated from $\mathrm{Prm}_{2}^{+/+}, \mathrm{Prm}^{+/-}$and $\mathrm{Prm}^{-/-}$males. Heatmap visualization of the top 50 differentially expressed (DE) genes and hierarchical clustering using the Euclidian distance clearly separated samples of $\mathrm{Prm}^{-/-}$males from controls as also verified by PCA analysis (Figure 6A,B). Most DE genes were stronger expressed in Prm $2^{-/-}$testes compared to controls. Mapping of upregulated genes to their chromosomal localization, showed a random distribution throughout the whole genome and no enrichment at distinct loci (Supplementary Figure S5A). This indicated that the protamine-mediated gene silencing during spermiogenesis might be incomplete upon loss of Prm2. In total, 81 genes were found to be upregulated and 13 genes to be downregulated in knockout testes compared to wildtype (Figure 6C). Among the upregulated genes, well-known regulators of protamine expression and translational activation were identified, e.g., Y-box binding protein $2(Y b x 2)$ and TAR binding-protein 2 (Tarbp2), probably resembling a compensation mechanism due to the lack of Prm2. However, gene ontology analysis on up- and downregulated gene sets did not identify enrichment of any biological processes, which might point towards secondary defects observed in the epididymis (Supplementary Figure S5B). These results support the notion that the induced ROS cascade is not initiated until sperm release from the seminiferous epithelium of the testis.

A

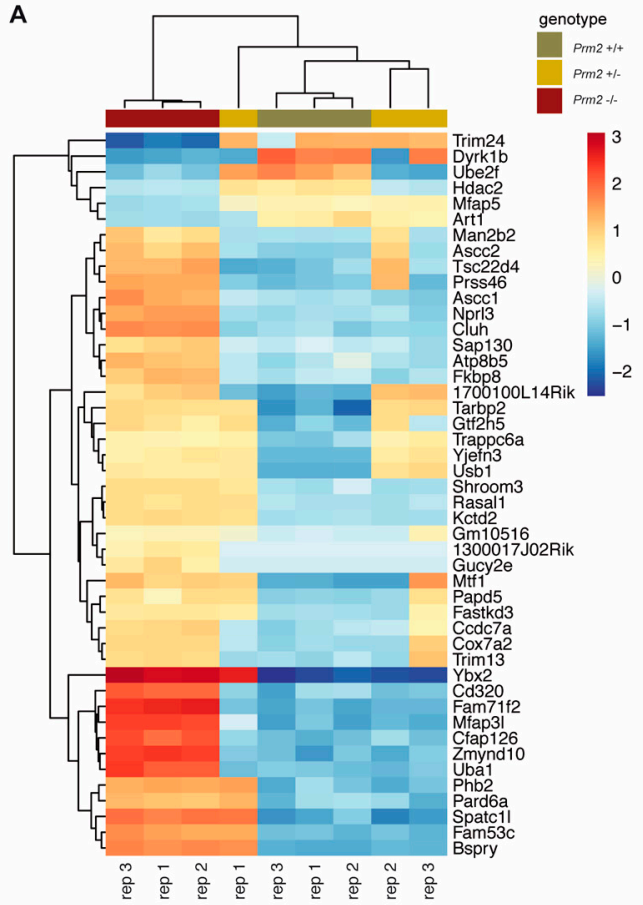

B

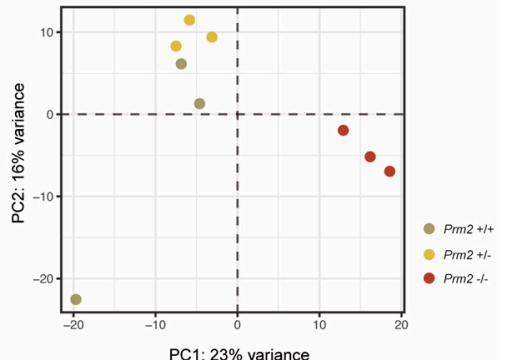

C

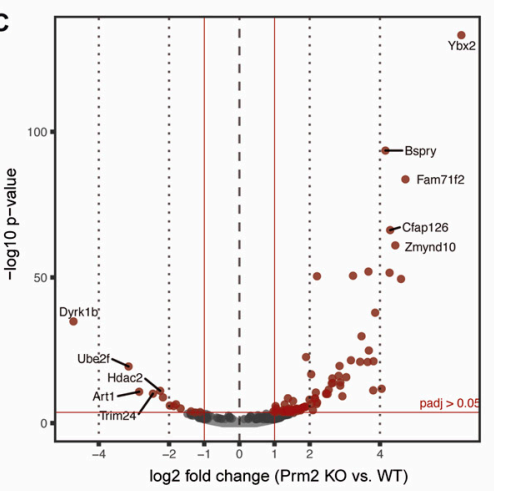

Figure 6. Changes in the testicular gene expression profile of Prm2-deficient mice. (A) Heatmap visualization of the top 50 DE genes (Prm2 $2^{-/-}$vs. Prm2 ${ }^{+/+}$) obtained by RNAseq on Prm2 $2^{+/+}, P_{r m} 2^{+/-}$ and $\mathrm{Prm}^{-/-}$testes. Three biological replicates (rep) were analyzed per genotype. (B) Principal component analysis (PCA). (C) Volcano plot displaying DE expressed genes (Prm $2^{-/-}$vs. Prm2 ${ }^{+/+}$) (adjusted p-value $<0.05, \log _{2}$ fold change $(\mathrm{LFC})>0.5$ ) between $\mathrm{Prm}^{+/+}$and $\mathrm{Prm} 2^{-/-}$testes.

\subsection{Blastocysts Stage Embryos Can Be Derived from ICSI of Prm2-Deficient Testicular Sperm}

Since Prm2-deficient testicular spermatids neither displayed oxidative DNA damage nor severe morphological abnormalities, we tested their fertilization potential in vitro. Testicular sperm were extracted from the seminiferous tubules and injected into unfertilized wildtype oocytes using ICSI. Of note, $10 \%$ of oocytes injected with Prm2-deficient sperm developed into blastocyst stage embryos 
within four days after injection (Figure 7A,B). Genotyping revealed all embryos to be heterozygous, indicating that Prm2-deficient sperm had fertilized the $\mathrm{Prm}^{+/+}$oocyte. (Figure 7C). Control injections with wildtype testicular spermatids displayed similar efficiencies for the induction of blastocyst stage embryos (Figure 7B). Thus, Prm2-deficient testicular sperm appear not only morphologically intact but also functionally capable to overcome infertility of $\mathrm{Prm}^{-{ }^{--}}$males using ART.

A

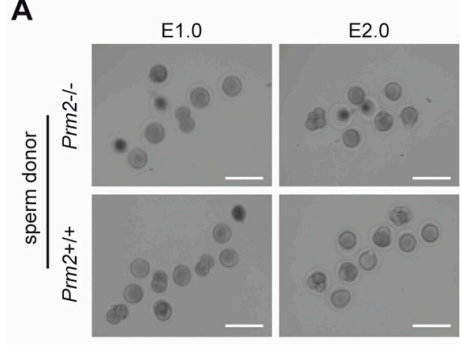

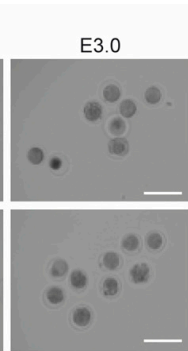

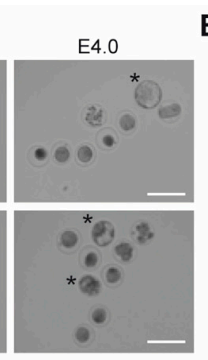

B

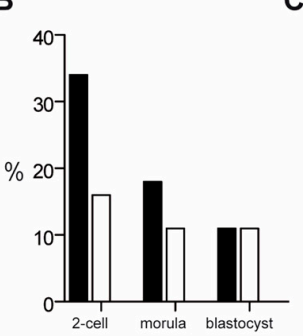

C

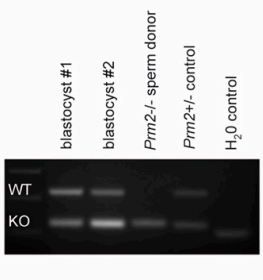

Figure 7. Infertility of Prm2-deficient males can be overcome by ICSI of testicular sperm. (A) Representative photomicrographs showing the in vitro development of oocytes upon ICSI of wildtype (bottom row) or Prm2-deficient sperm (top row) between embryonic day 1 and 4 (E1.0-E4.0). Blastocyst stage embryos are highlighted by asterisks. (B) ICSI statistics. (C) Genotyping of blastocysts derived from ICSI of $\mathrm{Prm}^{-/-}$sperm into wildtype oocytes. DNA from the $\mathrm{Prm} 2^{-/-}$sperm donor and a heterozygous animal served as controls.

\section{Discussion}

In the present study we utilized sperm proteomics to investigate the molecular origin of secondary sperm defects arising in consequence of abnormal sperm protamination. We demonstrate that loss of the sperm's antioxidant capacity induces a ROS destruction cascade during epididymal sperm maturation, ultimately causing oxidative DNA damage.

The connection of impaired sperm protamination and male subfertility is well-known for more than three decades. However, the molecular processes triggered by this impairment, finally leading to infertility, are mostly unknown, although being essential for the development of targeted treatment options. Here, our Prm2-deficient mouse lines serve as an ideal model for functional investigations, as they enable for the first time studies on a genetically and phenotypically uniform sperm population [29]. Protamine-induced DNA hypercondensation is proposed to protect the paternal genome from damaging environmental insults. However, the strong DNA degradation observed in human sperm with abnormal protamination and Prm2-deficient murine sperm implies an active destruction cascade as the underlying cause rather than a spontaneously induced damage. It is a longstanding matter of debate, how DNA damage is mechanistically induced [66]. Three mechanisms have been discussed in the past, including apoptotic processes, impaired repair of DNA strand breaks occurring during histone to protamine exchange and harmful effects of excessive ROS level [66]. Here we provide for the first time evidence that Prm2 deficiency triggers oxidative stress leading to DNA damage, and thus infertility. This was demonstrated by a strong positivity of epididymal sperm cells for 8-OHdG, a well-established marker for an oxidative stress-induced DNA base modification. Longstanding evidence exists for the implication of ROS in male fertility and sperm function. While low levels of ROS are required for sperm maturation, capacitation and acrosome reaction, exceeding levels have been strongly correlated with male infertility and sperm damage [67-69]. Besides strong DNA damage, Prm2-deficient sperm are completely immotile and display decreased viability due to severe defects in membrane integrity as well as detachment and partial loss of the acrosomal cap. Each of these aberrations is detrimental for physiological sperm function and fertility. These secondary effects are consistent with the known effects of oxidative stress. The sperm membrane contains a large amount of polyunsaturated fatty acids, which are susceptible to ROS-mediated lipid peroxidation, thereby demolishing membrane integrity and perturbing sperm motility in consequence [70]. Further, Prm2-deficient sperm display a strongly reduced head size, which has also been reported for sperm from Prm 2 chimeric mice [71]. This is 
unexpected in light of the DNA condensing function of protamines. However, it is in accordance with a Gpx5-deficient mouse model for oxidative stress, showing a decreased sperm volume and surface area as well [72]. Increased ROS levels result either from an increased production or a diminished antioxidant capacity. In Prm2-deficient sperm, significantly lower levels of the ROS scavenger enzymes SOD1 and PRDX5 are observed. SOD1 catalyzes the detoxification of superoxide radicals into hydrogen peroxide and oxygen. Studies in knock-out mice revealed that Sod1-deficient male mice remain fertile, however, sperm show impaired motility [64,73]. In consequence, in vivo such sperm cannot compete with wildtype sperm and display reduced fertilization ability in IVF experiments [64,74]. A correlation between SOD1 activity and sperm motility as well as DNA fragmentation is also reported for human sperm $[75,76]$. Alvarez et al. discuss superoxide dismutase (SOD) to be a key player for preventing human sperm from lipid peroxidation [70]. PRDX5 belongs to the class of peroxiredoxins, which act downstream of SOD and catalyze the detoxification of hydrogen peroxide as well as hydroperoxides and peroxynitrites [77]. Six peroxiredoxin isoforms have been identified, with an isoform-specific cellular localization. In humans, PRDX5 is enriched in the postacrosomal region of the sperm head and the mitochondrial sheath [78]. Inhibition of peroxiredoxin activity in murine sperm caused increased ROS levels, thereby underlining its role as antioxidant [63]. In mice, impaired peroxiredoxin activity results in DNA fragmentation and adversely affects sperm motility, viability, fertilization capacity and early embryonic development in mice [63]. In accordance, decreased peroxiredoxin levels are associated with male infertility and oxidative stress-mediated sperm damage in humans [79].

Taken together, the identified molecular changes in the proteome of Prm2-deficient sperm nicely delineate the underlying impact of ROS on sperm morphology and function - but how is Prm2 deficiency sensed and the ROS cascade induced? Interestingly, PRM2 and SOD1 share certain structural similarities. Both proteins harbor a zinc binding-site and are characterized by the formation of intramolecular disulfide bridges. Zinc incorporation into PRM2 is proposed to stabilize the chromatin structure of testicular sperm. However, during epididymal sperm maturation and enhanced disulfide bonding of protamines, zinc is released, as shown in stallion [80]. For SOD1, binding of zinc is essential for enzyme stability and function [81,82]. It is tempting to speculate that zinc ions released from PRM2 might confer stability of SOD1 in the epididymis, thereby ensuring its proper antioxidant function. So, loss of PRM2 might result in decreased zinc concentrations, ultimately causing enhanced degradation of SOD1, leading to an increase of toxic superoxide radicals. The observation that Prm2-deficient testes seem to be protected from ROS-mediated sperm destruction in contrast to epididymal compartments requires further analyses. Maybe the total antioxidant capacity [83] of the epididymis is lower, so that the decline of SOD1 and PRDX5 cannot be compensated. Since the epididymis is less immune privileged than the testis [84], the induced ROS cascade might be additionally fueled by infiltrating immune cells.

It remains to be investigated whether antioxidant supplementation would be sufficient to attenuate secondary sperm defects and restore fertility of Prm2-deficient males. In fact, antioxidant treatment of human IVF patients has been reported to improve sperm motility and semen parameters [85]. Of note, decreased sperm motility is not solely attributed to Prm2-deficient sperm, but has been consistently reported for Tnp1 and Tnp2 knockout mice as well as for Prm1 chimeras [26,86,87]. Although not directly proven, this is likely to be an oxidative stress-mediated response as well. Thus, it is tempting to speculate that a general checkpoint mechanism exists that controls the status of DNA hypercondensation and initiates the ROS response if needed. This response is finally exerted during epididymal transit as verified by the first occurrence of oxidative DNA damage, reduced head size and acrosomal malformations during passage through the epididymis. The preserved integrity of testicular sperm enables new treatment options. Here, ICSI with Prm2-deficient testicular sperm initiated proper embryonic development and blastocyst formation. In contrast, ICSI of Prm2-deficient epididymal sperm from Prm2 chimeras mostly resulted in an early embryonic arrest [71]. This confirms that the decline in chromatin integrity during epididymal sperm maturation directly impacts on early embryonic development. Similarly, ICSI with testicular sperm from Tnp $1^{-/-} \operatorname{Tn} p 2^{+/-}$males 
yielded higher implantation rates and more offspring than obtained by ICSI of Tnp1-/- Tnp $2^{+/-}$ cauda epididymal sperm [88]. In men, impaired sperm protamination is associated with recurrent miscarriages [89] and decreased fertilization rates in ART programs [23-25]. Thus, in light of the molecular mechanism provided in this study, ICSI with testicular sperm presents as only treatment option for subfertile men with impaired protamination and severe DNA fragmentation. In fact, a recent study proves that testicular sperm from patients with impaired protamination are superior to epididymal sperm in terms of fertilization rate and pregnancy outcome following ICSI [90].

Supplementary Materials: The following are available online at http://www.mdpi.com/2073-4409/9/8/1789/s1, Figure S1: Membrane integrity and sperm viability are decreased in Prm2-deficient mice; Figure S2: Normalization and quality controls of MS data; Figure S3: Profile Plot PRDX5; Figure S4: Prm2-deficient epididymal sperm display a decreased head size; Figure S5: Analyses on DE genes identified by RNAseq of Prm2-deficient testes [91].

Author Contributions: Conceptualization, S.S., K.S. and H.S.; methodology, S.S., C.T. and A.K.; formal analysis, F.S., S.S., L.A., A.K.; investigation, S.S., C.T., A.K.; resources, A.P. and A.B.; data curation, F.S. and L.A.; writing-original draft preparation, S.S. and H.S.; writing-review and editing, S.S. and H.S.; visualization, S.S., F.S. and L.A.; project administration, H.S. and K.S.; funding acquisition, H.S. and K.S. All authors have read and agreed to the published version of the manuscript.

Funding: This research was supported by a grant from the German Research foundation (DFG) to HS (SCH 503/15-2) and KS (STE 892/14-2).

Acknowledgments: We kindly thank the University of Bonn Core facilities for Next Generation Sequencing (NGS), Mass Spectrometry and Bioinformatics Data Analysis (CUBA) for their support. Further, we thank Gaby Beine, Angela Egert, Barbara Fröhlich, Andrea Jäger, Anna Pehlke and Susanne Steiner for excellent technical assistance.

Conflicts of Interest: The authors declare no conflict of interest. The funders had no role in the design of the study; in the collection, analyses, or interpretation of data; in the writing of the manuscript, or in the decision to publish the results.

\section{References}

1. Barral, S.; Morozumi, Y.; Tanaka, H.; Montellier, E.; Govin, J.; De Dieuleveult, M.; Charbonnier, G.; Couté, Y.; Puthier, D.; Buchou, T.; et al. Histone Variant H2A.L.2 Guides Transition Protein-Dependent Protamine Assembly in Male Germ Cells. Mol. Cell 2017, 66, 89-101. [CrossRef] [PubMed]

2. Hud, N.; Allen, M.; Downing, K.; Lee, J.; Balhorn, R. Identification of the Elemental Packing Unit of DNA in Mammalian Sperm Cells by Atomic Force Microscopy. Biochem. Biophys. Res. Commun. 1993, 193, 1347-1354. [CrossRef] [PubMed]

3. Ward, W.S. Function of sperm chromatin structural elements in fertilization and development. Mol. Hum. Reprod. 2009, 16, 30-36. [CrossRef] [PubMed]

4. Rathke, C.; Baarends, W.M.; Awe, S.; Renkawitz-Pohl, R. Chromatin dynamics during spermiogenesis. Biochim. Biophys. Acta Bioenerg. 2014, 1839, 155-168. [CrossRef]

5. Balhorn, R. A model for the structure of chromatin in mammalian sperm. J. Cell Boil. 1982, 93, $298-305$. [CrossRef]

6. Balhorn, R. The protamine family of sperm nuclear proteins. Genome Boil. 2007, 8, 227. [CrossRef]

7. Corzett, M.; Mazrimas, J.; Balhorn, R. Protamine 1: Protamine 2 stoichiometry in the sperm of eutherian mammals. Mol. Reprod. Dev. 2002, 61, 519-527. [CrossRef]

8. Balhorn, R.; Reed, S.; Tanphaichitr, N. Aberrant protamine 1/protamine 2 ratios in sperm of infertile human males. Experientia 1988, 44, 52-55. [CrossRef]

9. De Yebra, L.; Ballescà, J.L.; Vanrell, J.A.; Bassas, L.; Oliva, R. Complete selective absence of protamine P2 in humans. J. Boil. Chem. 1993, 268, 10553-10557.

10. Belokopytova, I.A.; Kostyleva, E.I.; Tomilin, A.N.; Vorob'Ev, V.I. Human male infertility may be due to a decrease of the protamine P2 content in sperm chromatin. Mol. Reprod. Dev. 1993, 34, 53-57. [CrossRef]

11. Khara, K.K.; Vlad, M.; Griffiths, M.; Kennedy, C.R. Human protamines and male infertility. J. Assist. Reprod. Genet. 1997, 14, 282-290. [CrossRef] [PubMed]

12. Steger, K.; Fink, L.; Failing, K.; Bohle, R.M.; Kliesch, S.; Weidner, W.; Bergmann, M. Decreased protamine-1 transcript levels in testes from infertile men. Mol. Hum. Reprod. 2003, 9, 331-336. [CrossRef] [PubMed]

13. Aoki, V.W.; Liu, L.; Carrell, D.T. Identification and evaluation of a novel sperm protamine abnormality in a population of infertile males. Hum. Reprod. 2005, 20, 1298-1306. [CrossRef] 
14. Oliva, R. Protamines and male infertility. Hum. Reprod. Update 2006, 12, 417-435. [CrossRef] [PubMed]

15. Ni, K.; Spiess, A.N.; Schuppe, H.C.; Steger, K. The impact of sperm protamine deficiency and sperm DNA damage on human male fertility: A systematic review and meta-analysis. J. Androl. 2016, 4, 789-799. [CrossRef] [PubMed]

16. Amor, H.; Zeyad, A.; Ben Ali, H.; Hammadeh, M. Protamines ratio (P1/P2) in spermatozoa as biomarker for male infertility. Fertil. Steril. 2017, 108, e142. [CrossRef]

17. Torregrosa, N.; Domínguez-Fandos, D.; Camejo, M.I.; Shirley, C.R.; Meistrich, M.L.; Ballescà, J.L.; Oliva, R. Protamine 2 precursors, protamine 1/protamine 2 ratio, DNA integrity and other sperm parameters in infertile patients. Hum. Reprod. 2006, 21, 2084-2089. [CrossRef]

18. Simon, L.; Castillo, J.; Oliva, R.; Lewis, S.E. Relationships between human sperm protamines, DNA damage and assisted reproduction outcomes. Reprod. Biomed. Online 2011, 23, 724-734. [CrossRef]

19. García-Peiró, A.; Martínez-Heredia, J.; Oliver-Bonet, M.; Abad, C.; Amengual, M.J.; Navarro, J.; Jones, C.; Coward, K.; Gosálvez, J.; Benet, J. Protamine 1 to protamine 2 ratio correlates with dynamic aspects of DNA fragmentation in human sperm. Fertil. Steril. 2011, 95, 105-109. [CrossRef]

20. Aoki, V.W.; Moskovtsev, S.I.; Willis, J.; Mullen, B.; Carrell, D.T.; Liu, L. DNA Integrity Is Compromised in Protamine-Deficient Human Sperm. J. Androl. 2005, 26, 741-748. [CrossRef]

21. Aoki, V.W.; Emery, B.R.; Liu, L.; Carrell, D.T. Protamine Levels Vary Between Individual Sperm Cells of Infertile Human Males and Correlate with Viability and DNA Integrity. J. Androl. 2006, 27, 890-898. [CrossRef] [PubMed]

22. Iranpour, F.G. The effects of protamine deficiency on ultrastructure of human sperm nucleus. Adv. Biomed. Res. 2014, 3, 24. [CrossRef] [PubMed]

23. Nasr-Esfahani, M.H.; Salehi, M.; Razavi, S.; Mardani, M.; Bahramian, H.; Steger, K.; Oreizi, F. Effect of protamine-2 deficiency on ICSI outcome. Reprod. Biomed. Online 2004, 9, 652-658. [CrossRef]

24. Aoki, V.W.; Liu, L.; Jones, K.P.; Hatasaka, H.H.; Gibson, M.; Peterson, C.M.; Carrell, D.T. Sperm protamine 1/protamine 2 ratios are related to in vitro fertilization pregnancy rates and predictive of fertilization ability. Fertil. Steril. 2006, 86, 1408-1415. [CrossRef]

25. Rogenhofer, N.; Dansranjavin, T.; Schorsch, M.; Spiess, A.; Wang, H.; Von Schönfeldt, V.; Cappallo-Obermann, H.; Baukloh, V.; Yang, H.; Paradowska, A.; et al. The sperm protamine mRNA ratio as a clinical parameter to estimate the fertilizing potential of men taking part in an ART programme. Hum. Reprod. 2013, 28, 969-978. [CrossRef]

26. Cho, C.; Willis, W.D.; Goulding, E.H.; Jungha, H.; Choi, Y.; Hecht, N.B.; Eddy, E.M. Haploinsufficiency of protamine-1 or -2 causes infertility in mice. Nat. Genet. 2001, 28, 82-86. [CrossRef]

27. Mashiko, D.; Fujihara, Y.; Satouh, Y.; Miyata, H.; Isotani, A.; Ikawa, M. Generation of mutant mice by pronuclear injection of circular plasmid expressing Cas9 and single guided RNA. Sci. Rep. 2013, 3, 3355. [CrossRef]

28. Takeda, N.; Yoshinaga, K.; Furushima, K.; Takamune, K.; Li, Z.; Abe, S.I.; Aizawa, S.I.; Yamamura, K.I. Viable offspring obtained from Prm1-deficient sperm in mice. Sci. Rep. 2016, 6, 27409. [CrossRef]

29. Schneider, S.; Balbach, M.; Jikeli, J.F.; Fietz, D.; Nettersheim, D.; Jostes, S.; Schmidt, R.; Kressin, M.; Bergmann, M.; Wachten, D.; et al. Re-visiting the Protamine-2 locus: Deletion, but not haploinsufficiency, renders male mice infertile. Sci. Rep. 2016, 6, 1-13. [CrossRef]

30. Ren, Z.X.; You, W.; Wu, S.; Poetsch, A.; Xu, C. Secretomic analyses of Ruminiclostridium papyrosolvens reveal its enzymatic basis for lignocellulose degradation. Biotechnol. Biofuels 2019, 12, 183. [CrossRef]

31. Mellacheruvu, D.; Wright, Z.; Couzens, A.L.; Lambert, J.P.; St-Denis, N.A.; Li, T.; Miteva, Y.V.; Hauri, S.; Sardiu, M.E.; Low, T.Y.; et al. The CRAPome: A contaminant repository for affinity purification-mass spectrometry data. Nat. Methods 2013, 10, 730-736. [CrossRef] [PubMed]

32. The, M.; MacCoss, M.J.; Noble, W.S.; Käll, L. Fast and Accurate Protein False Discovery Rates on Large-Scale Proteomics Data Sets with Percolator 3.0. J. Am. Soc. Mass Spectrom. 2016, 27, 1719-1727. [CrossRef] [PubMed]

33. Perez-Riverol, Y.; Csordas, A.; Bai, J.; Llinares, M.B.; Hewapathirana, S.; Kundu, D.J.; Inuganti, A.; Griss, J.; Mayer, G.; Eisenacher, M.; et al. The PRIDE database and related tools and resources in 2019: Improving support for quantification data. Nucleic Acids Res. 2018, 47, D442-D450. [CrossRef] [PubMed]

34. Anonymous. The R Project for Statistical Computing. Available online: http://www.r-project.org/ (accessed on 13 February 2012). 
35. Huber, W.; Von Heydebreck, A.; Sültmann, H.; Poustka, A.; Vingron, M. Variance stabilization applied to microarray data calibration and to the quantification of differential expression. Bioinformatics 2002, 18, S96-S104. [CrossRef]

36. Le, S.; Josse, J.; Husson, F. FactoMineR: An RPackage for Multivariate Analysis. J. Stat. Softw. 2008, 25, 1-18. [CrossRef]

37. Ritchie, M.E.; Phipson, B.; Wu, D.; Hu, Y.; Law, C.W.; Shi, W.; Smyth, G.K. limma powers differential expression analyses for RNA-sequencing and microarray studies. Nucleic Acids Res. 2015, 43, e47. [CrossRef]

38. Wickham, H. ggplot2: Elegant Graphics for Data Analysis; Springer: New York, NY, USA, 2016.

39. Gu, Z.; Eils, R.; Schlesner, M. Complex heatmaps reveal patterns and correlations in multidimensional genomic data. Bioinformatics 2016, 32, 2847-2849. [CrossRef]

40. Nettersheim, D.; Heukamp, L.C.; Fronhoffs, F.; Grewe, M.J.; Haas, N.; Waha, A.; Honecker, F.; Waha, A.; Kristiansen, G.; Schorle, H. Analysis of TET Expression/Activity and $5 \mathrm{mC}$ Oxidation during Normal and Malignant Germ Cell Development. PLoS ONE 2013, 8, e82881. [CrossRef]

41. Weyrich, A. Preparation of Genomic DNA from Mammalian Sperm. Curr. Protoc. Mol. Boil. $2012,98$. [CrossRef]

42. Moskovtsev, S.I.; Librach, C.L. Methods of sperm vitality assessment. Methods Mol. Biol. 2013, 927, 13-19.

43. Skinner, B.M.; Rathje, C.C.; Bacon, J.; Johnson, E.E.P.; Larson, E.L.; Kopania, E.E.K.; Good, J.M.; Yousafzai, G.; Affara, N.A.; Ellis, P.J. A high-throughput method for unbiased quantitation and categorisation of nuclear morphology. Biol. Reprod. 2018, 312470. [CrossRef]

44. Kim, D.; Langmead, B.; Salzberg, S. HISAT: A fast spliced aligner with low memory requirements. Nat. Methods 2015, 12, 357-360. [CrossRef] [PubMed]

45. Pertea, M.; Pertea, G.M.; Antonescu, C.M.; Chang, T.C.; Mendell, J.T.; Salzberg, S. StringTie enables improved reconstruction of a transcriptome from RNA-seq reads. Nat. Biotechnol. 2015, 33, 290-295. [CrossRef] [PubMed]

46. Love, M.I.; Huber, W.; Anders, S. Moderated estimation of fold change and dispersion for RNA-seq data with DESeq2. Genome Biol. BioMed Cent. 2014, 15, 002832. [CrossRef] [PubMed]

47. Durinck, S.; Moreau, Y.; Kasprzyk, A.; Davis, S.; De Moor, B.; Brazma, A.; Huber, W. BioMart and Bioconductor: A powerful link between biological databases and microarray data analysis. Bioinformatics 2005, 21, 3439-3440. [CrossRef]

48. Bourgon, R.; Gentleman, R.; Huber, W. Reply to Talloen et al.: Independent filtering is a generic approach that needs domain specific adaptation. Proc. Natl. Acad. Sci. USA 2010, 107, E175. [CrossRef]

49. Mi, H.; Huang, X.; Muruganujan, A.; Tang, H.; Mills, C.; Kang, D.; Thomas, P.D. PANTHER version 11: Expanded annotation data from Gene Ontology and Reactome pathways, and data analysis tool enhancements. Nucleic Acids Res. 2016, 45, D183-D189. [CrossRef]

50. Ashburner, M.; Ball, C.A.; Blake, J.A.; Botstein, D.; Butler, H.; Cherry, J.M.; Davis, A.P.; Dolinski, K.; Dwight, S.S.; Eppig, J.T.; et al. Gene Ontology: Tool for the unification of biology. Nat. Genet. 2000, 25, 25-29. [CrossRef]

51. Fabregat, A.; Sidiropoulos, K.; Garapati, P.; Gillespie, M.; Hausmann, K.; Haw, R.; Jassal, B.; Jupe, S.; Korninger, F.; Mckay, S.J.; et al. The Reactome Pathway Knowledgebase. Nucleic Acids Res. 2018, 46, D649-D655. [CrossRef]

52. Edgar, R.; Domrachev, M.; Lash, A.E. Gene Expression Omnibus: NCBI gene expression and hybridization array data repository. Nucleic Acids Res. 2002, 30, 207-210. [CrossRef]

53. Kimura, Y.; Yanagimachi, R. Mouse oocytes injected with testicular spermatozoa or round spermatids can develop into normal offspring. Development 1995, 121, 2397-2405. [PubMed]

54. Yoshida, N.; Perry, A.C. Piezo-actuated mouse intracytoplasmic sperm injection (ICSI). Nat. Protoc. 2007, 2, 296-304. [CrossRef] [PubMed]

55. Scavizzi, F.; Ryder, E.; Newman, S.; Raspa, M.; Gleeson, D.; Wardle-Jones, H.; Montoliu, L.; Fernández, A.; Dessain, M.L.; Larrigaldie, V.; et al. Blastocyst genotyping for quality control of mouse mutant archives: An ethical and economical approach. Transgenic Res. 2015, 24, 921-927. [CrossRef] [PubMed]

56. Stein, K.K.; Go, J.C.; Lane, W.S.; Primàkoff, P.; Myles, D.G. Proteomic analysis of sperm regions that mediate sperm-egg interactions. Proteomics 2006, 6, 3533-3543. [CrossRef] [PubMed]

57. Cao, W.; Gerton, G.L.; Moss, S.B. Proteomic Profiling of Accessory Structures from the Mouse Sperm Flagellum. Mol. Cell. Proteom. 2006, 5, 801-810. [CrossRef] 
58. Baker, M.A.; Hetherington, L.; Reeves, G.M.; Aitken, R.J. The mouse sperm proteome characterized via IPG strip prefractionation and LC-MS/MS identification. Proteomics 2008, 8, 1720-1730. [CrossRef]

59. Dorus, S.; Wasbrough, E.R.; Busby, J.; Wilkin, E.C.; Karr, T.L. Sperm Proteomics Reveals Intensified Selection on Mouse Sperm Membrane and Acrosome Genes. Mol. Boil. Evol. 2010, 27, 1235-1246. [CrossRef]

60. Castillo, J.; Jodar, M.; Oliva, R. The contribution of human sperm proteins to the development and epigenome of the preimplantation embryo. Hum. Reprod. Update 2018, 24, 535-555. [CrossRef]

61. Cao, W.; Aghajanian, H.K.; Haig-Ladewig, L.A.; Gerton, G.L. Sorbitol can fuel mouse sperm motility and protein tyrosine phosphorylation via sorbitol dehydrogenase. Biol. Reprod. 2009, 80, 124-133. [CrossRef]

62. Klemm, U.; Müller-Esterl, W.; Engel, W. Acrosin, the peculiar sperm-specific serine protease. Qual. Life Res. 1991, 87, 635-641. [CrossRef]

63. Ryu, D.Y.; Kim, K.U.; Kwon, W.S.; Rahman, S.; Khatun, A.; Pang, M.G. Peroxiredoxin activity is a major landmark of male fertility. Sci. Rep. 2017, 7, 17174. [CrossRef] [PubMed]

64. Garratt, M.; Bathgate, R.; De Graaf, S.; Brooks, R.C. Copper-zinc superoxide dismutase deficiency impairs sperm motility and in vivo fertility. Reproduction 2013, 146, 297-304. [CrossRef] [PubMed]

65. Walbrecq, G.; Wang, B.; Becker, S.; Hannotiau, A.; Fransen, M.; Knoops, B. Antioxidant cytoprotection by peroxisomal peroxiredoxin-5. Free Radic. Boil. Med. 2015, 84, 215-226. [CrossRef] [PubMed]

66. Carrell, D.T.; Emery, B.R.; Hammoud, S. Altered protamine expression and diminished spermatogenesis: What is the link? Hum. Reprod. Update 2007, 13, 313-327. [CrossRef] [PubMed]

67. Tremellen, K.P. Oxidative stress and male infertility-A clinical perspective. Hum. Reprod. Update 2008, 14, 243-258. [CrossRef] [PubMed]

68. Aitken, R.J. Free radicals, lipid peroxidation and sperm function. Reprod. Fertil. Dev. 1995, 7, 659-668. [CrossRef]

69. Aitken, R.J.; Jones, K.; Robertson, S.A. Reactive Oxygen Species and Sperm Function-In Sickness and In Health. J. Androl. 2012, 33, 1096-1106. [CrossRef]

70. Alvarez, J.G.; Touchstone, J.C.; Blasco, L.; Storey, B.T. Spontaneous Lipid Peroxidation and Production of Hydrogen Peroxide and Superoxide in Human Spermatozoa Superoxide Dismutase as Major Enzyme Protectant Against Oxygen Toxicity. J. Androl. 1987, 8, 338-348. [CrossRef]

71. Cho, C.; Jung-Ha, H.; Willis, W.D.; Goulding, E.H.; Stein, P.; Xu, Z.; Schultz, R.M.; Hecht, N.B.; Eddy, E.M. Protamine 2 Deficiency Leads to Sperm DNA Damage and Embryo Death in Mice1. Boil. Reprod. 2003, 69, 211-217. [CrossRef]

72. Champroux, A.; Damon-Soubeyrand, C.; Goubely, C.; Bravard, S.; Henry-Berger, J.; Guiton, R.; Saez, F.; Drevet, J.R.; Kocer, A. Nuclear Integrity but Not Topology of Mouse Sperm Chromosome is Affected by Oxidative DNA Damage. Genes 2018, 9, 501. [CrossRef]

73. Ho, Y.S.; Gargano, M.; Cao, J.; Bronson, R.T.; Heimler, I.; Hutz, R.J. Reduced Fertility in Female Mice Lacking Copper-Zinc Superoxide Dismutase. J. Boil. Chem. 1998, 273, 7765-7769. [CrossRef] [PubMed]

74. Tsunoda, S.; Kawano, N.; Miyado, K.; Kimura, N.; Fujii, J. Impaired Fertilizing Ability of Superoxide Dismutase 1-Deficient Mouse Sperm During In Vitro Fertilization1. Boil. Reprod. 2012, 87, 121. [CrossRef] [PubMed]

75. Murawski, M.; Saczko, J.; Marcinkowska, A.; Chwiłkowska, A.; Gryboś, M.; Banaś, T. Evaluation of superoxide dismutase activity and its impact on semen quality parameters of infertile men. Folia Histochem. Cytobiol. 2007, 45, 23-126.

76. Yan, L.; Liu, J.; Wu, S.; Zhang, S.; Ji, G.; Gu, A.H. Seminal superoxide dismutase activity and its relationship with semen quality and SOD gene polymorphism. J. Assist. Reprod. Genet. 2014, 31, 549-554. [CrossRef]

77. Wood, Z.A.; Schröder, E.; Harris, J.R.; Poole, L.B. Structure, mechanism and regulation of peroxiredoxins. Trends Biochem. Sci. 2003, 28, 32-40. [CrossRef]

78. O'Flaherty, C.; De Souza, A.R. Hydrogen peroxide modifies human sperm peroxiredoxins in a dose-dependent manner. Boil. Reprod. 2010, 84, 238-247. [CrossRef]

79. Gong, S.; Gabriel, M.C.S.; Zini, A.; Chan, P.; O'Flaherty, C. Low Amounts and High Thiol Oxidation of Peroxiredoxins in Spermatozoa from Infertile Men. J. Androl. 2012, 33, 1342-1351. [CrossRef]

80. Dias, G.; Retamal, C.; Tobella, L.; Arnholdt, A.; López, M. Nuclear status of immature and mature stallion spermatozoa. Theriogenology 2006, 66, 354-365. [CrossRef]

81. Ding, F.; Dokholyan, N.V. Dynamical roles of metal ions and the disulfide bond in Cu, Zn superoxide dismutase folding and aggregation. Proc. Natl. Acad. Sci. USA 2008, 105, 19696-19701. [CrossRef] 
82. Miao, L.; Clair, D.K.S. Regulation of superoxide dismutase genes: Implications in disease. Free Radic. Boil. Med. 2009, 47, 344-356. [CrossRef]

83. Gupta, S.; Finelli, R.; Agarwal, A.; Henkel, R. Total antioxidant capacity-Relevance, methods and clinical implications. Andrologia 2020, 2, e13624. [CrossRef] [PubMed]

84. Guiton, R.; Henry-Berger, J.; Drevet, J.R. The immunobiology of the mammalian epididymis: The black box is now open. Basic Clin. Androl. 2013, 23, 8. [CrossRef] [PubMed]

85. Wirleitner, B.; Vanderzwalmen, P.; Stecher, A.; Spitzer, D.; Schuff, M.; Schwerda, D.; Bach, M.; Schechinger, B.; Zech, N.H. Dietary Supplementation of Antioxidants Improves Semen Quality of IVF Patients in Terms of Motility, Sperm Count, and Nuclear Vacuolization. Int. J. Vitam. Nutr. Res. 2012, 82, 391-398. [CrossRef] [PubMed]

86. Yu, Y.E.; Zhang, Y.; Unni, E.; Shirley, C.R.; Deng, J.M.; Russell, L.D.; Weil, M.M.; Behringer, R.R.; Meistrich, M.L. Abnormal spermatogenesis and reduced fertility in transition nuclear protein 1-deficient mice. Proc. Natl. Acad. Sci. USA 2000, 97, 4683-4688. [CrossRef]

87. Adham, I.M.; Nayernia, K.; Burkhardt-Göttges, E.; Topaloglu, O.; Dixkens, C.; Holstein, A.F.; Engel, W. Teratozoospermia in mice lacking the transition protein 2 (Tnp2). Mol. Hum. Reprod. 2001, 7, 513-520. [CrossRef]

88. Suganuma, R.; Yanagimachi, R.; Meistrich, M.L. Decline in fertility of mouse sperm with abnormal chromatin during epididymal passage as revealed by ICSI. Hum. Reprod. 2005, 20, 3101-3108. [CrossRef]

89. Rogenhofer, N.; Ott, J.; Pilatz, A.; Wolf, J.; Thaler, C.J.; Windischbauer, L.; Schagdarsurengin, U.; Steger, K.; von Schonfeldt, V. Unexplained recurrent miscarriages are associated with an aberrant sperm protamine mRNA content. Hum. Reprod. 2017, 32, 1574-1582. [CrossRef]

90. Sarasa, J.; Enciso, M.; García, L.; Leza, A.; Steger, K.; Aizpurua, J. Comparison of ART outcomes in men with altered mRNA protamine 1/protamine 2 ratio undergoing intracytoplasmic sperm injection with ejaculated and testicular spermatozoa. Asian J. Androl. 2020. [CrossRef]

91. Kin, T.; Ono, Y. Idiographica: A general-purpose web application to build idiograms on-demand for human, mouse and rat. Bioinformatics 2007, 23, 2945-2946. [CrossRef]

(C) 2020 by the authors. Licensee MDPI, Basel, Switzerland. This article is an open access article distributed under the terms and conditions of the Creative Commons Attribution (CC BY) license (http://creativecommons.org/licenses/by/4.0/). 